BMJ Open

Diabetes

Research

\& Care

\title{
Patients' perspectives on the barriers to referral after telescreening for diabetic retinopathy in communities
}

\author{
Xiaofeng Zhu, ${ }^{1,2}$ Yi Xu, ${ }^{1,2}$ Lina Lu, ${ }^{1,2}$ Haidong Zou (i) 1,2
}

To cite: Zhu X, Xu Y, Lu L, et al. Patients' perspectives on the barriers to referral after telescreening for diabetic retinopathy in communities. BMJ Open Diab Res Care 2020;8:e000970. doi:10.1136/ bmjdrc-2019-000970

\section{- Additional material is published online only. To view please visit the journal online (http://dx.doi.org/10.1136/ bmjdrc-2019-000970).}

XFZ and YX contributed equally.

Received 9 0ctober 2019 Revised 11 December 2019 Accepted 18 December 2019

D) Check for updates

(C) Author(s) (or their employer(s)) 2020. Re-use permitted under CC BY-NC. No commercial re-use. See rights and permissions. Published by BMJ.

${ }^{1}$ Department of Preventative Ophthalmology, Shanghai Eye Disease Prevention and Treatment Center/Shanghai Eye Hospital, Shanghai, China ${ }^{2}$ Department of Ophthalmology, Shanghai General Hospital, Shanghai Jiao Tong University School of Medicine, Shanghai, China

Correspondence to Dr Haidong Zou; zouhaidong@hotmail.com and Dr Lina Lu;

lulina781019@qq.com

\section{ABSTRACT}

Objective To understand the referral completion and explore the associated barriers to the referral after telescreening for diabetic retinopathy (DR) among people with vision-threatening DR (VTDR).

Research design and methods All participants with VTDR after DR telescreening in the communities completed the self-reported questionnaires to assess referral completion and their perspectives on referral barriers. Sociodemographic characteristics and perceived barriers related to incomplete referrals were identified by conducting univariate analysis and multiple logistic regression model. The final model was then built to predict incomplete referral.

Results Of the 3362 participants, $46.1 \%$ had incomplete referral. Old age and lower education level showed significant association with incomplete referral. Almost all participants had at least one barrier during the referral process. Knowledge-related and attitude-related barriers, including 'Too old to want any more treatment', 'Difficulty in getting time to referral', 'No serious illness requiring treatment at present', 'My eyes are okay', 'Distrust the recommended hospital' and 'Have not been diagnosed or treated before', and logistics-related barrier 'Mobility or transportation difficulties' showed significant association with incomplete referral.

Conclusions The issue of incomplete referral after DR telescreening is serious among individuals with VTDR, particularly in the elder and low education level population. The negativity of knowledge-related and attitude-related factors might be more prominent than logistic barriers in predicting incomplete referral. Therefore, new strategies to improve the compliance with referral assist in optimizing the referral accessibility, and the ongoing educational support to improve the awareness of disease and increase the effectiveness of physician-patient communication.

\section{INTRODUCTION}

The progression of diabetes leads to diabetic eye disease, particularly diabetic retinopathy (DR), which affects over a third of people with diabetes and causes a heavy global burden of the disease. Many developing countries like China and India are facing an alarming increase in the incidence of diabetes and DR due to rapid industrialization and urbanization. ${ }^{1}$ According to community-based studies in China, $9.4 \%-43.1 \%$ of people with diabetes

\section{Significance of this study}

What is already known about this subject?

- Telemedicine has been applied in diabetic retinopathy (DR) screening.

- High rates of incomplete referral after telescreening for DR, and patients factors or healthcare system factors might contribute to the barriers for accessing the eye care services.

What are the new findings?

- Referral completion and perceived barriers to the referral were assessed in a large representative sample with vision-threatening DR (VTDR) from the communities after DR telescreening.

- The issue of incomplete referral is serious among the individuals with VTDR, particularly in the elder and low education level population.

- The negativity of knowledge-related and attituderelated factors might be more prominent than logistic barriers in predicting the incomplete referrals.

How might these results change the focus of research or clinical practice?

- Novel strategies for improving the compliance with referral assist in optimizing the referral accessibility and the ongoing educational support to improve the awareness of disease, and increase the effectiveness of physician-patient communication.

are expected to have DR, while approximately $5.2 \%-6.5 \%$ patients with diabetes might have vision-threatening DR (VTDR). ${ }^{2-4}$

Vision loss and blindness due to DR are almost entirely preventable through regular eye examinations and timely management. ${ }^{5}$ Unfortunately, the rate of early detection and treatment of DR in low-income and middleincome countries has remained very low; this is due to an increase in the population with diabetes, lack of eye care resources, and limited access to quality and affordable eye care. ${ }^{6-8}$ Telemedicine is a promising tool to address this public health issue, and has the potential to facilitate more widespread and cost-effective DR screening. ${ }^{9-11}$ Meanwhile, many successful telemedicine programmes 
have been established in high-income countries such as Europe and USA, and the integration of DR telescreening into the healthcare system as a regular service has been promoted deliberately by the governments. ${ }^{12} 13 \mathrm{In}$ Shanghai, the first telescreening system for DR in experimental community health service centers (CHSCs) has been built by us in 2009. ${ }^{14}$ A comprehensive management system for diabetic eye diseases has been established through the Shanghai Diabetic Eye Study (SDES) since 2015, which focused on telescreening, referral, treatment, and follow-up. ${ }^{1516}$

The effectiveness and efficiency of DR telescreening depends on the referral rate. ${ }^{17}$ Few studies have reported significant differences in the referral rates for eye care after implementation of eye screening programmes, which ranged from $11 \%$ to $60 \%{ }^{18-21}$ Patient-level or healthcare system-level factors might contribute to the barriers for accessing eye care services and high rates of incomplete referrals. This study aimed to understand referral completion and explore the barriers related to the referral after DR telescreening among patients with diabetes with VTDR. The targeted population and perceived barriers that are at high risk of incomplete referral were focused on to develop the policies and interventions in order to improve the use of eye care services after DR telescreening.

\section{RESEARCH DESIGN AND METHODS}

\section{Shanghai Diabetic Eye Study}

The SDES was implemented in all 240 CHSCs from 2015 to 2017. Sampling was carried out by a proportional sampling plan based on name, age, and sex, such that each individual with diabetes aged 35 years and above under community-based diabetes management will have an equal chance to participate in the study. A total of 211469 people with diabetes (32\% coverage rate) have been enrolled. ${ }^{16}$ The SDES has established a referral relationship between several CHSCs and the nearby superior (secondary or tertiary) hospitals in the same region. The referral hospitals were instructed to set up a special process so as to accept the referred participants for further examination and treatment. The SDES process is shown in online supplementary figure S1.

\section{Study participants}

All participants were from SDES. The inclusion criteria were as follows: patients (1) Who completed DR telescreening. (2) Graded with VTDR by remote retinal image reading. (3) Who were referred to a superior hospital within a specified time (60 days). (4) Who independently completed the self-reported questionnaire. We informed the eligible participants regarding the investigation time and place in detail and a door-to-door survey was performed for the participants with limited physical mobility.

This study adhered to the tenets of the Declaration of Helsinki. Written informed consent was obtained from all participants before enrollment.

\section{Development of referral questionnaires}

The survey instrument used questions adapted from the China Census 2010 and a survey that evaluated and predicted the attendance of people with DR in the SDES to annual eye examinations. ${ }^{16}{ }^{22}$ Additionally, key informant interviews were conducted of people with DR and of eye care practitioners to assess their views regarding the frequent barriers to referrals. The referral survey was a pilot study tested on a sample of 50 patients with VTDR in order to modify the survey items. The final referral survey focused on sociodemographic characteristics, and the perceived barriers (such as knowledge-related, attituderelated, and logistics-related factors) to the referral, and included an open-ended question as the main reason for incomplete referral (online supplementary table S1). The participants were asked how much they agreed with a statement about each barrier on a four-point scale, ranging from strongly disagree to strongly agree (eg, 'My life is too busy for referral').

\section{Data analysis}

The data were analyzed using SPSS V.22.0 (IBM, Armonk, New York, USA), and a value of $\mathrm{p}<0.05$ was considered to be statistically significant. Participants who self-reported that they have not visited the superior hospitals within 60 days were categorized as incomplete referral. For each barrier to the referral, the responses were dichotomized between 'Agree' or 'Strongly Agree' as 'yes' and 'Agree' or 'Strongly Agree' as 'no'. The barriers that are positively phrased (eg, 'I trust the recommended superior hospital.') are reverse coded.

First, univariate associations along with the variables (sociodemographic characteristics and perceived barriers to referral) of incomplete referrals were tested using $\chi^{2}$ or independent-sample t-tests. Second, the variables with significant associations in univariate analysis entered a multiple logistic regression model to identify the variables that are significantly related to incomplete referral. A final model was then developed to assess the predictive validity that combined significant sociodemographic characteristics and perceived barriers to the referral in multivariate logistic regression with self-reported incomplete referral as the dependent variable. Furthermore, the frequency distribution, median number of barriers to the referral, and the cumulative effect of barriers were evaluated by examining the associations with incomplete referrals. In addition, the electronic medical records of a random sample of 400 participants were reviewed to test the validity of self-reports as a measure of incomplete referral.

\section{RESULTS}

\section{Sample characteristics}

Approximately 4140 (2.1\% detection rate) potential participants with VTDR were identified through DR telescreening. Among these, 3362 (81.2\%) participants with response rate were included in the referral survey. Most of these $(2986 / 3362,88.8 \%)$ completed the questionnaires via interviewer-administered surveys due to poor 
visual acuity and low education levels, and the remaining participants completed the questionnaires by themselves. The participants' age ranged from 35 years to 93 years, while $79.7 \%$ are older than 60 years of age. The duration of diabetes ranged from 0.25 years to 52 years, with $54.8 \%$ with diabetes for more than 10 years. Glycated hemoglobin (HbAlc) levels higher than $7.0 \%(53 \mathrm{mmol} / \mathrm{mol})$ were reported by $73.0 \%$ of participants. Furthermore, the number of participants with vision loss $(25.6 \%)$ or blindness $(18.4 \%)$ was high. Overall, $53.9 \%$ of the referrals $(1812 / 3362)$ were considered complete. The participants with incomplete referrals were significantly older, with recently diagnosed diabetes, lower education level and milder DR grading. In addition, these factors showed significant association with incomplete referrals, except DR grading, and entered the multivariate logistic regression model (table 1$)$. For all except three records $(3 / 400$, $99.3 \%)$, the participants' reports of complete referrals were confirmed as accurate by electronic medical records.

\section{Perceived barriers associated with incomplete referrals}

A total percentage of $97.2 \%(3267 / 3362)$ participants experienced at least one barrier during the referral process. The most frequent barriers cited by the participants were about knowledge-related and attitude-related factors, which were as follows: 'Too much trouble to see an ophthalmologist in a superior hospital', 'My eyes are okay', 'Have not been diagnosed or treated before', 'No serious illness requiring treatment at present', and 'Fear of examination and treatment'. In addition, 'Distrust the recommended hospital', 'Depression', and 'Too old to want any more treatment' were considered as the least frequent barriers (table 2). Among the participants with incomplete referrals, $88.3 \%(1368 / 1550)$ provided substantive responses for incomplete referral. Review of these reasons resulted in the creation of 18 categories (online supplementary figure S2); $97.1 \%$ (1328/1368) of the reasons provided were covered by items in our survey, while $2.9 \%(40 / 1368)$ were not, which included suffering from other diseases $(21 / 40)$, forgetting $(11 / 40)$, relocating $(6 / 40)$, communication difficulties $(1 / 40)$, and weather $(1 / 40)$.

When the perceived barriers by the participants who had complete and incomplete referrals were compared, the barriers with the strongest associations with incomplete referrals differed from those that are most frequently mentioned (figure 1). For instance, 'Distrust the recommended hospital' and 'Too old to want any more treatment' were the less frequent barriers, but had stronger associations with incomplete referrals in the multivariate model. Other significant associations included 'Difficulty in getting time to referral', 'No serious illness need treatment at present', 'My eyes are okay', and 'Mobility or transportation difficulties'. In contrast, 'Have been diagnosed or treated before' was significantly associated with complete referral (table 2). The final model provided $68.1 \%$ accuracy and explained approximately 22\% of the variance in classifying the participants (Nagelkerke's
$\left.\mathrm{R}^{2}=0.215\right)$. All the seven barriers discussed above and two sociodemographic characteristics (older age and lower education level) were considered significant predictors of incomplete referrals in this model (table 3 ).

\section{Cumulative effects of barriers}

The number of barriers to the referral as experienced by the participants is shown in figure 2. Both participants with complete and incomplete referrals have experienced a median of four barriers. The participants who experienced the lowest quartile of barriers (three or more barriers) more likely had incomplete referrals than others (51.6\% vs $31.9 \%$, OR 2.28). In addition, when compared with the participants who experienced the median number of barriers to referral (four or more barriers) and the others (53.3\% vs $37.5 \%$, OR 1.91), the participants with the highest quartile of barriers to referral (six or more barriers) and the others $(55.8 \%$ vs $43.0 \%$, OR 1.67) showed approximately the same odds of incomplete referral. Moreover, those participants who experienced one or more significant barriers were nearly twice as likely to have incomplete referral than others ( $48.4 \%$ vs $27.7 \%$, OR 2.46 ), (online supplementary table S2).

\section{DISCUSSION}

Our study is the first to assess referral completion and perceived barriers affecting referral behavior after DR telescreening in a large representative sample with a high response rate from communities. The outcomes indicated that although DR telescreening greatly improved the accessibility to eye care services among individuals with diabetes, the subsequent referral rates were not high. On an average, only one of two participants with VTDR reported completed referral and received appropriate eye care after DR telescreening. Moreover, the referral rate varied greatly among individuals based on different sociodemographic characteristics and perceived barriers to the referral. ${ }^{23}$

Sociodemographic characteristics, including old age and low education levels were regarded as significant predictors of incomplete referral as shown in the previous studies. ${ }^{24}{ }^{25}$ Older individuals with diabetes are more susceptible to VTDR, but with limited understanding of the diseases and the reasons for referral. These findings help to inform the frequency of surveillance of older and less educated individuals with VTDR. Participants with a more recent diagnosis of diabetes, better presentation of visual acuity or milder DR grading showed no significant association with incomplete referral in our study, and were inconsistent with the previous study results. Generally, individuals with longer duration of diabetes have greater odds of visual impairment from DR, and require an ophthalmology referral. ${ }^{20}{ }^{26}$ These findings provided evidence that DR telescreening in the communities covers more people who are young or recently diagnosed with diabetes, and improves disease awareness even in 
Table 1 Descriptives, and univariate and multivariate analyses of sociodemographic and clinical-related variables for incomplete referrals in the cross-sectional survey

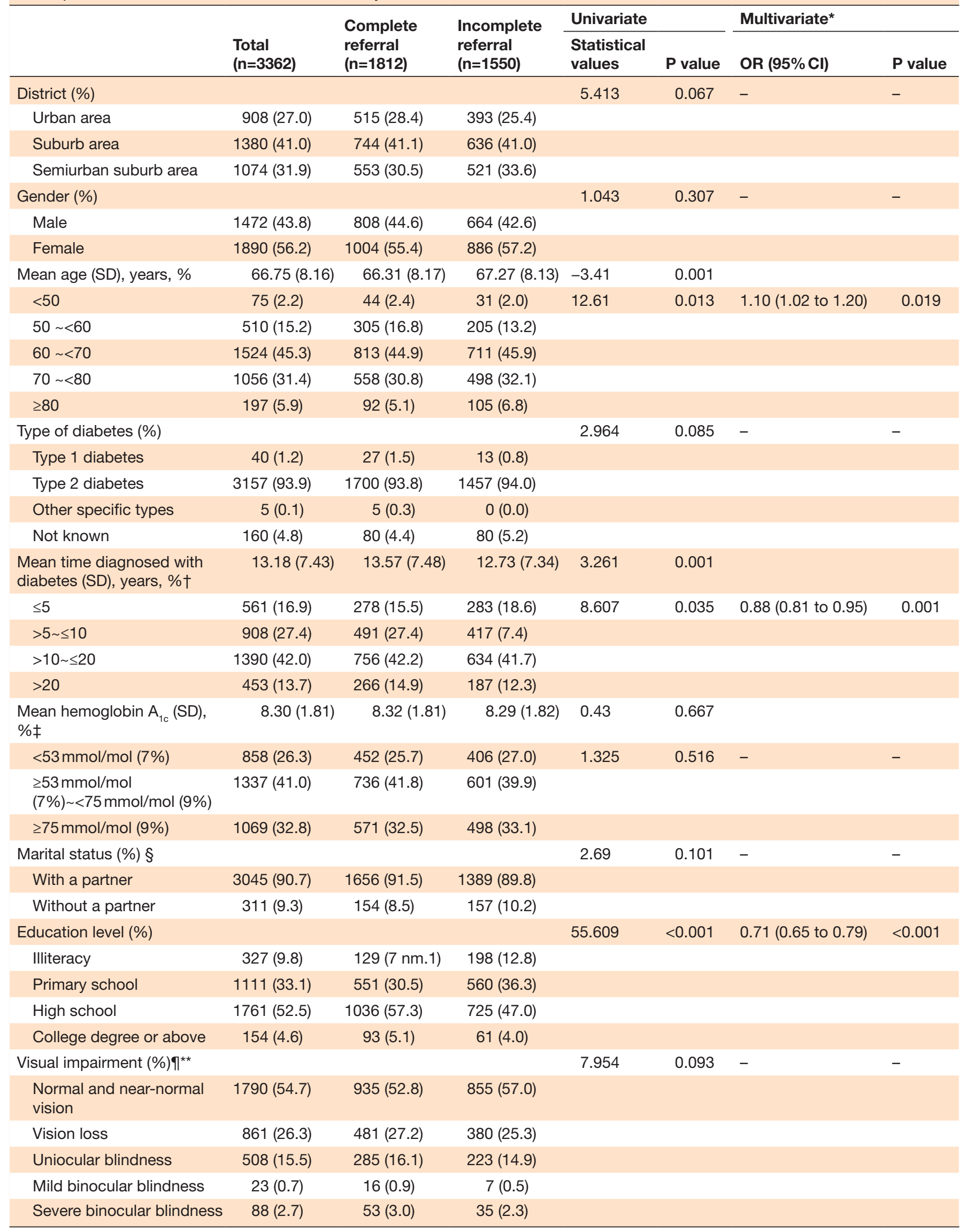




\begin{tabular}{|c|c|c|c|c|c|c|c|}
\hline & \multirow[b]{2}{*}{$\begin{array}{l}\text { Total } \\
(n=3362)\end{array}$} & \multirow{2}{*}{$\begin{array}{l}\text { Complete } \\
\text { referral } \\
(n=1812)\end{array}$} & \multirow{2}{*}{$\begin{array}{l}\text { Incomplete } \\
\text { referral } \\
(n=1550)\end{array}$} & \multicolumn{2}{|l|}{ Univariate } & \multicolumn{2}{|l|}{ Multivariate* } \\
\hline & & & & $\begin{array}{l}\text { Statistical } \\
\text { values }\end{array}$ & $P$ value & OR $(95 \% \mathrm{Cl})$ & $P$ value \\
\hline $\begin{array}{l}\text { Mild/moderate NPDR with } \\
\text { DME }\end{array}$ & $510(15.2)$ & 276 (15.2) & 234 (15.1) & & & & \\
\hline PDR & $629(18.7)$ & $371(20.5)$ & $258(16.6)$ & & & & \\
\hline
\end{tabular}

Variable not included in multivariate analysis because no significant result was obtained in univariate analysis.

${ }^{*}$ Results of multivariate logistic regression analysis for significant variables were included in the final model after using a stepwise backward elimination.

†Overall, in the cross-sectional survey, $\mathrm{n}=3312$ (50 participants did not report their time of diagnosis with diabetes); complete referral, $\mathrm{n}=1791$; incomplete referral, $\mathrm{n}=1521$.

†Overall, in the cross-sectional survey, $n=3264$ (98 participants had no data on their most recent test result); complete referral, $n=1759$; incomplete referral, $\mathrm{n}=1505$.

§With a partner included married and domestic partnership, and without a partner included single, separated, divorced and widowed. ๆVisual impairment was graded on the presenting vision acuity. Normal and near-normal vision $\geq 0.3$ in both eyes; vision loss $0.1 \sim<0.3$ in the worse eye and $\geq 0.1$ in the better eye; uniocular blindness $<0.1$ in the worse and $\geq 0.1$ in the better eye; mild binocular blindness $<0.1$ in the worse and $0.05 \sim 0.1$ in the better eye; severe binocular blindness $<0.05$ in both eyes.

${ }^{\star *}$ Overall, in the cross-sectional survey $n=3270$ (92 participants had no data on presenting visual acuity); complete referral $n=1770$; incomplete referral $\mathrm{n}=1500$.

DME, diabetic macular edema; NPDR, non-proliferative diabetic retinopathy; PDR, proliferative diabetic retinopathy.

Table 2 Univariate and multivariate analyses of the perceived barriers to the referrals among participants with visionthreatening diabetic retinopathy after telescreening $(n=3362)$

\begin{tabular}{|c|c|c|c|c|c|}
\hline \multirow[b]{2}{*}{ Barrier statement } & \multirow[b]{2}{*}{ Numbers (\%) } & \multicolumn{2}{|l|}{ Univariate } & \multicolumn{2}{|l|}{ Multivariate * } \\
\hline & & OR $(95 \% \mathrm{Cl})$ & $P$ value & OR (95\% Cl) & $P$ value \\
\hline \multicolumn{6}{|l|}{ Knowledge-related and attitude-related factors } \\
\hline $\begin{array}{l}\text { Too much trouble to see an ophthalmologist } \\
\text { in a superior hospital }\end{array}$ & 2075 (61.9) & $1.52(1.32$ to 1.76$)$ & $<0.001$ & 1.09 (0.92 to 1.28$)$ & 0.325 \\
\hline My eyes are okay & $1513(45.0)$ & 2.29 (2.00 to 2.63$)$ & $<0.001$ & 1.77 (1.51 to 2.09$)$ & $<0.001$ \\
\hline $\begin{array}{l}\text { Have been diagnosed or treated before } \\
\text { telescreening }\end{array}$ & $1273(38.0)$ & 0.47 (0.41 to 0.55$)$ & $<0.001$ & $0.52(0.45$ to 0.61$)$ & $<0.001$ \\
\hline $\begin{array}{l}\text { No serious illness needs treatment at } \\
\text { present }\end{array}$ & $1269(37.8)$ & 3.28 (2.83 to 3.79$)$ & $<0.001$ & 2.01 (1.70 to 2.38$)$ & $<0.001$ \\
\hline Fear of examination and treatment & $1152(34.3)$ & $0.88(0.76$ to 1.01$)$ & 0.077 & - & - \\
\hline $\begin{array}{l}\text { No effective treatment for diabetic } \\
\text { retinopathy at present }\end{array}$ & $1147(34.2)$ & 0.90 (0.78 to 1.04$)$ & 0.149 & - & - \\
\hline No response to previous treatment & $941(28.4)$ & 0.75 (0.65 to 0.88$)$ & $<0.001$ & 0.98 (0.80 to 1.20$)$ & 0.855 \\
\hline Difficulty in getting time to referral & $692(20.6)$ & 3.06 (2.57 to 3.66$)$ & $<0.001$ & 2.151 .77 to 2.61$)$ & $<0.001$ \\
\hline Good eyesight in the other eye & $688(20.6)$ & 1.37 (1.16 to 1.62$)$ & $<0.001$ & 1.05 (0.87 to 1.27$)$ & 1.052 \\
\hline Too old to want any more treatment & $477(14.2)$ & 3.03 (2.46 to 3.72$)$ & $<0.001$ & 2.58 (2.05 to 3.26$)$ & $<0.001$ \\
\hline Depression & $477(14.2)$ & 0.89 (0.73 to 1.08$)$ & 0.234 & - & - \\
\hline Distrust the recommended hospital & $239(7.1)$ & $1.72(1.32$ to 2.24$)$ & $<0.001$ & 1.53 (1.13 to 2.06$)$ & 0.006 \\
\hline \multicolumn{6}{|l|}{ Logistics-related factors } \\
\hline Mobility or transportation difficulties & $1134(33.9)$ & 1.24 (1.08 to 1.43$)$ & 0.003 & $1.32(1.12$ to 1.55$)$ & 0.001 \\
\hline Financial difficulties & $781(23.2)$ & 0.93 (0.79 to 1.09$)$ & 0.36 & - & - \\
\hline Lack of an escort & $636(18.9)$ & 1.96 (1.64 to 2.33$)$ & $<0.001$ & $1.18(0.95$ to 1.47$)$ & 0.143 \\
\hline
\end{tabular}

Barrier not included in multivariate analysis due to no significant result in univariate analysis.

${ }^{*}$ Results of multivariate logistic regression analysis for significant barriers that are included in the final model after using a stepwise backward elimination. 


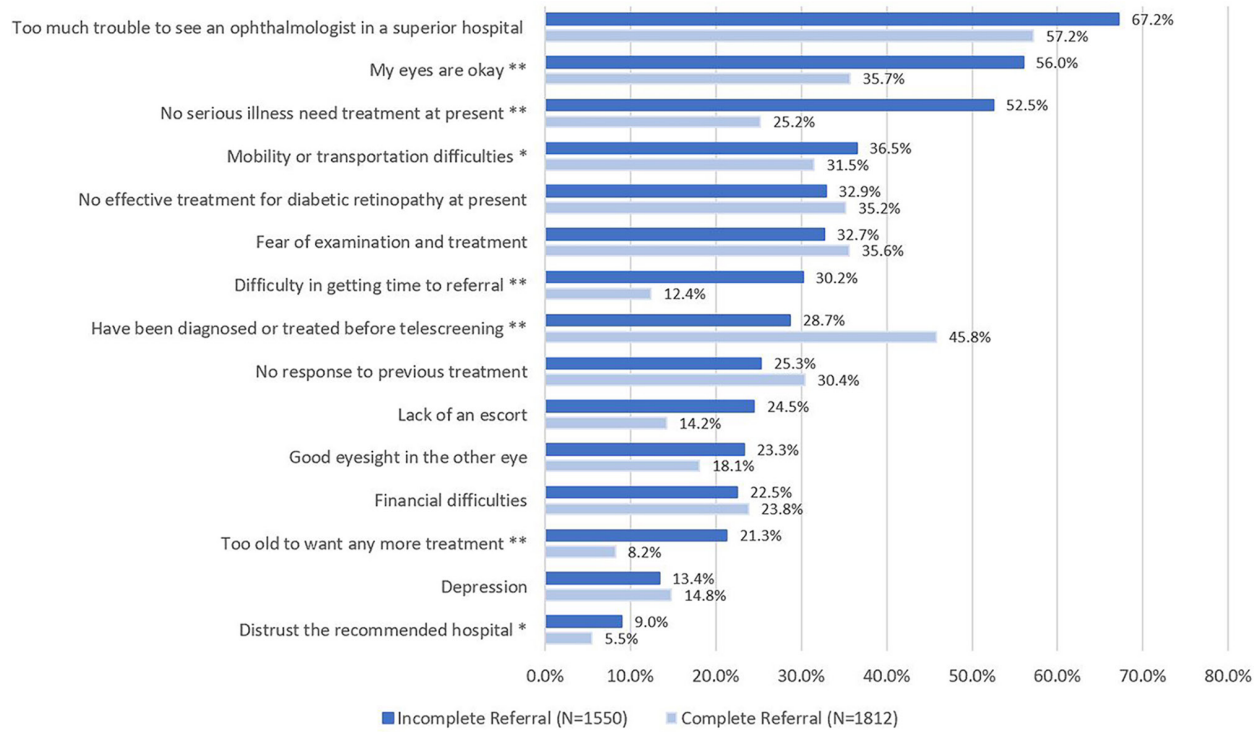

Figure 1 Comparison of perceived barriers by the participants who had complete and incomplete referrals using a multiple logistic regression model. ${ }^{\star} \mathrm{p}<0.01 ;{ }^{*} \mathrm{p}<0.001$.

the asymptomatic stage. ${ }^{6}$ Besides, living areas, which is a common reason for delayed follow-up in people with $\mathrm{DR},{ }^{21}{ }^{24}$ showed no association with perceived risk of incomplete referral in our study. It is probably due to the referral system of the SDES that connected the CHSC with the nearby superior hospital, making eye care services more accessible for individuals with VTDR. In addition, although there was no significant association between

Table 3 Final model of logistic regression analysis by using stepwise backward elimination for significant sociodemographic characteristics and perceived barriers to the referral

\begin{tabular}{llr}
\hline & OR $(95 \%$ Cl) & P value \\
\hline $\begin{array}{l}\text { Sociodemographic } \\
\text { characteristics }\end{array}$ & & \\
\hline Age & $1.13(1.04$ to 1.24$)$ & 0.007 \\
\hline $\begin{array}{l}\text { Education level } \\
\text { Perceived barriers }\end{array}$ & $0.77(0.68$ to 0.87$)$ & $<0.001$ \\
\hline $\begin{array}{l}\text { Too old to want any } \\
\text { more treatment }\end{array}$ & $2.38(1.88$ to 3.01$)$ & $<0.001$ \\
\hline $\begin{array}{l}\text { Difficulty in getting time } \\
\text { to referral }\end{array}$ & $2.15(1.76$ to 2.61$)$ & $<0.001$ \\
$\begin{array}{l}\text { No serious illness needs } \\
\text { treatment at present }\end{array}$ & $2.07(1.75$ to 2.44$)$ & $<0.001$ \\
\hline $\begin{array}{l}\text { My eyes are okay } \\
\text { Distrust the } \\
\text { recommended hospital }\end{array}$ & $1.85(1.57$ to 2.18$)$ & $<0.001$ \\
\hline $\begin{array}{l}\text { Mobility or } \\
\text { transportation difficulties }\end{array}$ & $1.22(1.03$ to 1.44$)$ & 0.021 \\
\hline $\begin{array}{l}\text { Have been diagnosed } \\
\text { or treated before } \\
\text { telescreening }\end{array}$ & $0.54(0.46$ to 0.64$)$ & $<0.001$ \\
\hline
\end{tabular}

HbA1c levels and incomplete referral, nearly half of the participants with better glucose control had incomplete referrals. Therefore, people with diabetes should control their blood glucose levels to completely prevent the progression of DR, and regular eye examination and timely referral are also considered more important. ${ }^{27}$ Furthermore, no association between sex, type of diabetes and marital status and incomplete referral was observed as reported in previous studies. ${ }^{21} 2328$

Consistent with previous studies, the findings of the present study suggested that knowledge-related and attitude-related factors might be more prominent than logistic barriers in predicting incomplete referrals among participants with VTDR. ${ }^{23}{ }^{25}$ At first, participants with incomplete referrals more significantly believed that they were 'Too old to need any more treatment', and reported that 'My eyes are okay' and 'No serious illness need treatment at present'. ${ }^{19} 2930$ In addition, 'Difficulty getting time to referral' was significantly cited by more participants with incomplete referral; however, most of the participants in our study were of retirement age (28/32). These findings indicated a significant lack of awareness of the participants with DR, which is particularly more in low-income and middle-income countries. ${ }^{21}{ }^{24}$ If participants with diabetes were unaware of the severe prognosis of DR and have not yet experienced any functional vision changes, they potentially would not have understood the purpose of the referral. ${ }^{31}$ This highlights the importance of educating people with DR to ensure understanding of the necessity and benefits of early treatment. Extensive studies in patients with chronic eye diseases showed persistent efforts towards patient education in order to improve medication compliance. ${ }^{32-34}$

The other significant knowledge-related and attituderelated barrier associated with incomplete referral was 'Distrust the recommended hospital'. Previous studies 
$20.0 \%$

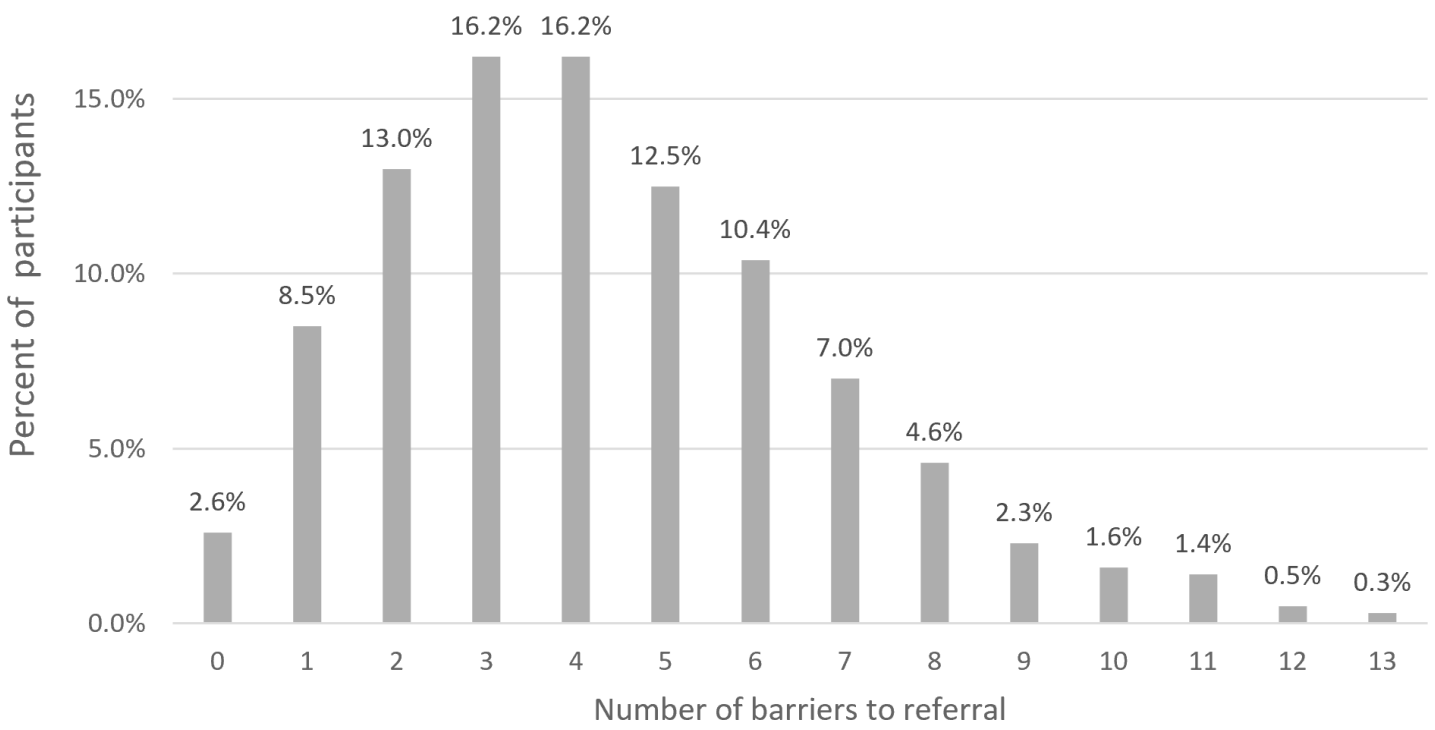

Figure 2 Number of barriers to referral as experienced by the participants $(n=3362)$.

have shown that trust acts as a critical element in medical care. ${ }^{3035}$ In China, people generally believe that doctors in tertiary/specialized hospitals have ample clinical experience and higher level of diagnosis and treatment when compared with others in secondary hospitals and tertiary/ specialized hospitals with more advanced equipment for diagnosis and therapy. ${ }^{36}$ Therefore, while establishing the regional referral systems, increasing the publicity and capacity of the recommended hospitals and informationsharing between primary hospitals and superior hospitals are considerably important.

The remaining significant knowledge-related and attitude-related factor 'Have been diagnosed or treated before telescreening' showed significant association with complete referral, indicating that past experience of eye care could increase the patients' motivation for referral. Previous studies have shown that increasing effective physician-patient communication assists in explaining the purpose that further diagnosis and treatment might improve the referral rates after DR telescreening. ${ }^{21} 23$

The only significant logistic barrier associated with incomplete referral was 'Mobility or transportation difficulties', which was consistent with that of the previous studies which had poor utilization of referral services. ${ }^{29} 30$ At a societal level, there is a need for affordable and accessible transportation services for individuals with DR seeking eye care. For health practitioners, understanding the underlying reasons regarding the patient's concerns and fears in greater depth and optimizing the referral accessibility (eg, door-to-door examination, community volunteering development) might be able to address this logistic barrier.

Although financial factors, one of the most common logistic barriers to eye care service, particularly in the low-income and middle-income countries, ${ }^{172137}$ showed no significant association with incomplete referral in our study. This difference was possibly because that the SDES provided low-cost or free eye care services for participants with VTDR during the referral process. However, the effect of participants' income and indirect financial burden (eg, transportation costs and missed days of work) on referral compliance has not been investigated in our study. Also a distinction between the capacity to pay and willingness to pay for healthcare services has been put forward in previous studies. ${ }^{38} 39$ Moreover, although 'Depression' did not predict incomplete referral in our study, previous studies have reported that depressed people had lower compliance with recommended behavior and lifestyle changes in order to reduce the risk of adverse events. ${ }^{40}$ There might be a need for clinicians to systematically assess the mental health of people with DR and direct them to have appropriate therapeutic services. Therefore, more evidence should be obtained on these two barriers in future studies.

Of note, $61.9 \%$ of the participants have complained about 'Too much trouble to see an ophthalmologist in a superior hospital', which improved the clarity of the referral process and clinical efficiency that is limiting the impact of incomplete referral. For instance, superior hospitals can set up outpatient services especially for people with VTDR, and promote appointment service for referrals to avoid long waiting times. ${ }^{41}$ In addition, offering laser treatment as an outreach service in primary hospitals could be considered. ${ }^{21}$ Furthermore, more than half of the participants who experienced three or more barriers had incomplete referrals, and the chance to complete referral was half of the participants who experienced at least one significant barrier after DR telescreening. Therefore, much attention should be paid to people with DR who have any significant barriers and three or more perceived barriers during the referral process. 
From the perspective of health economics, DR telescreening and referral contribute to considerable saving when compared with the 'no prevention' strategy. ${ }^{42}$ The ultimate cost of blindness from DR progression far outweighs the marginal cost of referral as well as follow-up. ${ }^{24}$ In 2017 , the average cost for DR onset till the treatment of advanced stage in Shanghai is approximately US\$710, which included the cost of operation, examination, and drug. In SDES, a price of only US $\$ 22$ has been estimated for detecting early stage DR by telescreening in an individual in the community based on actual resource consumption. Therefore, early detection and intervention effectively prevents disease progression, thus saving health expenses greatly. ${ }^{10}$

However, the present study had several limitations. First, participants likely experienced other barriers to referral that were not addressed in our study, although our survey was based on key informant interviews and the referral questionnaire. Second, data collection relied on participants' self-reports of referral, presenting a potential for recall bias. Third, the participants were surveyed about the perceived barriers to referral about 2 months after receiving the referral recommendations. Thus, they might have forgotten the detailed barriers that they experienced or might have outweighed some barriers more than others after they had completed their referral. Furthermore, our study did not investigate adherence to treatment or follow-up, limiting the applicability of the findings.

\section{CONCLUSIONS}

The issue of incomplete referral after DR telescreening is shown to be more serious among participants with VTDR, particularly in the elder and low education level population. The negativity of knowledge-related and attituderelated factors might be more prominent than logistic barriers for predicting incomplete referrals. Therefore, new strategies for improving compliance with referral after DR telescreening should optimize referral accessibility, and the ongoing educational support to improve the awareness of the disease and increase the effectiveness of physician-patient communication.

Acknowledgements The SDES Research Group gratefully acknowledges the commitment and dedication of the participants of the SDES.

Contributors XFZ and YX analyzed and interpreted the data and wrote the manuscript. HDZ contributed to data management, statistical guidance, and reviewed and approved the manuscript. HDZ and LNL reviewed and approved the manuscript. HDZ, XFZ and LNL designed the study and reviewed and approved the manuscript. HDZ is the guarantor of this work and had full access to all the data in the study and takes responsibility for the integrity of the data and the accuracy of the data analysis.

Funding This work was supported by the National Natural Science Foundation of China (grant number: 81700844, 81670898), Shanghai Municipal Education Commission—Gaofeng Clinical Medicine Grant Support (grant number: 20172022), the Project of Shanghai Shen Kang Hospital Development Centre (grant number: SHDC2018110), The Shanghai Three Year Public Health Action Program (grant number: GWIV-3.3), Shanghai General Hosptial (grant number: CTCCR-2018Z01), and Science and Technology Commission of Shanghai Municipality (grant number:19DZ2205700).
Competing interests None declared.

Patient consent for publication Obtained.

Ethics approval Institutional review board of Shanghai General Hospital.

Provenance and peer review Not commissioned; externally peer reviewed.

Data availability statement Data are available upon reasonable request. All data relevant to the study are included in the article or uploaded as supplementary information. Some or all data generated or used during the study are available from the corresponding author by request. (zouhaidong@hotmail.com).

Open access This is an open access article distributed in accordance with the Creative Commons Attribution Non Commercial (CC BY-NC 4.0) license, which permits others to distribute, remix, adapt, build upon this work non-commercially, and license their derivative works on different terms, provided the original work is properly cited, appropriate credit is given, any changes made indicated, and the use is non-commercial. See: http://creativecommons.org/licenses/by-nc/4.0/.

ORCID iD

Haidong Zou http://orcid.org/0000-0002-6831-7560

\section{REFERENCES}

1 International Diabetes Federation. IDF diabetes Atlas 9th edition [article online], 2019. Available: http://www.diabetesatlas.org/ [Accessed 27 Sep 2019].

2 Pang C, Jia L, Jiang S, et al. Determination of diabetic retinopathy prevalence and associated risk factors in Chinese diabetic and prediabetic subjects: Shanghai diabetic complications study. Diabetes Metab Res Rev 2012;28:276-83.

3 Wang FH, Liang YB, Zhang F, et al. Prevalence of diabetic retinopathy in rural China: the Handan eye study. Ophthalmology 2009:116:461-7.

4 Xie XW, Xu L, Jonas JB, et al. Prevalence of diabetic retinopathy among subjects with known diabetes in China: the Beijing eye study. Eur J Ophthalmol 2009;19:91-9.

5 Baker RS, Watkins NL, Wilson MR, et al. Demographic and clinical characteristics of patients with diabetes presenting to an urban public hospital ophthalmology clinic. Ophthalmology 1998;105:1373-9.

6 Jin P, Peng J, Zou H, et al. A five-year prospective study of diabetic retinopathy progression in chinese type 2 diabetes patients with "well-controlled" blood glucose. PLoS One 2015;10:e0123449.

7 Gulshan V, Rajan RP, Widner K, et al. Performance of a DeepLearning algorithm vs manual grading for detecting diabetic retinopathy in India. JAMA Ophthalmol 2019;137:987-93.

8 Wong TY, Sabanayagam C. Strategies to tackle the global burden of diabetic retinopathy: from epidemiology to artificial intelligence. Ophthalmologica 2020;243:9-20.

9 Rathi S, Tsui E, Mehta N, et al. The current state of Teleophthalmology in the United States. Ophthalmology 2017:124:1729-34.

10 Chua J, Lim CXY, Wong TY, et al. Diabetic retinopathy in the AsiaPacific. Asia Pac J Ophthalmol 2018;7:3-16.

11 Delgoshaei B, Mobinizadeh M, Mojdekar R, et al. Telemedicine: a systematic review of economic evaluations. Med J Islam Repub Iran 2017;31:113:761.

12 Liu Y, Torres Diaz A, Benkert R. Scaling up Teleophthalmology for diabetic eye screening: opportunities for widespread implementation in the USA. Curr Diab Rep 2019;19:74.

13 Labiris G, Panagiotopoulou E-K, Kozobolis VP. A systematic review of teleophthalmological studies in Europe. Int $J$ Ophthalmol 2018;11:314-25.

14 Peng J, Zou H, Wang W, et al. Implementation and first-year screening results of an ocular telehealth system for diabetic retinopathy in China. BMC Health Serv Res 2011;11:250.

$15 \mathrm{Xu}$ Y, Wang Y, Liu B, et al. The diagnostic accuracy of an intelligent and automated fundus disease image assessment system with lesion quantitative function (SmartEye) in diabetic patients. BMC Ophthalmol 2019;19:184.

16 Zhu $\mathrm{X}, \mathrm{Xu} \mathrm{Y}, \mathrm{Xu} \mathrm{X}$, et al. Psychometric assessment and application of the Chinese version of the compliance with annual diabetic eye exams survey in people with diabetic retinopathy. Diabet Med 2020;37:84-94

17 Ferreira GDA, Rezende MA, Meneghim RLFdeS, et al. Barriers between community screening for visual problems and treatments in a tertiary center. Rev Saúde Pública 2018;52:85.

18 Friedman DS, Cassard SD, Williams SK, et al. Outcomes of a vision screening program for underserved populations in the United States. Ophthalmic Epidemiol 2013;20:201-11. 
19 Looker HC, Nyangoma SO, Cromie DT, et al. Rates of referable eye disease in the Scottish national diabetic retinopathy screening programme. Br J Ophthalmol 2014;98:790-5.

20 Jani PD, Forbes L, Choudhury A, et al. Evaluation of diabetic retinal screening and factors for ophthalmology referral in a telemedicine network. JAMA Ophthalmol 2017;135:706-14.

21 Mtuya C, Cleland CR, Philippin $\mathrm{H}$, et al. Reasons for poor follow-up of diabetic retinopathy patients after screening in Tanzania: a crosssectional study. BMC Ophthalmol 2016;16:115.

22 National Bureau of Statistics of China. 2010 Population Census [article online], 2013. Available: http://www.stats.gov.cn/english/ Statisticaldata/CensusData/ [Accessed 27 Sep 2019].

23 Thompson AC, Thompson MO, Young DL, et al. Barriers to follow-up and strategies to improve adherence to appointments for care of chronic eye diseases. Invest Ophthalmol Vis Sci 2015;56:4324-31.

24 Vengadesan N, Ahmad M, Sindal MD, et al. Delayed followup in patients with diabetic retinopathy in South India: social factors and impact on disease progression. Indian J Ophthalmol 2017;65:376-84.

$25 \mathrm{Kim}$ YK, Jeoung JW, Park KH. Understanding the reasons for loss to follow-up in patients with glaucoma at a tertiary referral teaching hospital in Korea. Br J Ophthalmol 2017;101:1059-65.

26 Schoenfeld ER, Greene JM, Wu SY, et al. Patterns of adherence to diabetes vision care guidelines: baseline findings from the diabetic retinopathy awareness program. Ophthalmology 2001;108:563-71.

27 Wong TY, Klein R, Islam FMA, et al. Diabetic retinopathy in a multi-ethnic cohort in the United States. Am J Ophthalmol 2006;141:446-55.

28 Zuckerman KE, Perrin JM, Hobrecker K, et al. Barriers to specialty care and specialty referral completion in the community health center setting. J Pediatr 2013;162:409-14.

29 Khanna RC, Kim S, Giridhar P, et al. Barriers to uptake of referral services from secondary care to tertiary care and its associated factors in L V Prasad eye Institute network in southern India: a cross-sectional study. BMJ Open 2018;8:e020687.

30 Owsley C, McGwin G, Scilley K, et al. Perceived barriers to care and attitudes about vision and eye care: focus groups with older
African Americans and eye care providers. Invest Ophthalmol Vis Sci 2006;47:2797-802.

31 Aleo CL, Murchison AP, Dai Y, et al. Improving eye care followup adherence in diabetic patients with ocular abnormalities: the effectiveness of patient contracts in a free, pharmacy-based eye screening. Public Health 2015;129:996-9.

32 Marmamula S, Khanna RC, Shekhar K, et al. A population-based cross-sectional study of barriers to uptake of eye care services in South India: the rapid assessment of visual impairment (RAVI) project. BMJ Open 2014;4:e005125.

33 Matimba A, Woodward R, Tambo E, et al. Tele-Ophthalmology: opportunities for improving diabetes eye care in resource- and specialist-limited sub-Saharan African countries. J Telemed Telecare 2016;22:311-6.

34 McVeigh KA, Vakros G. The eye drop chart: a pilot study for improving administration of and compliance with topical treatments in glaucoma patients. Clin Ophthalmol 2015;9:813-9.

35 Du J, Lu X, Wang Y, et al. Mutual referral: a survey of GPs in Beijing. Fam Pract 2012;29:441-7.

36 Eggleston K, Ling L, Qingyue M, et al. Health service delivery in China: a literature review. Health Econ 2008;17:149-65.

37 Unwin N, Whiting D, Roglic G. Social determinants of diabetes and challenges of prevention. Lancet 2010;375:2204-5.

38 Kessy JP, Lewallen S. Poverty as a barrier to accessing cataract surgery: a study from Tanzania. Br J Ophthalmol 2007;91:1114-6.

39 Melese M, Alemayehu W, Friedlander E, et al. Indirect costs associated with accessing eye care services as a barrier to service use in Ethiopia. Trop Med Int Health 2004;9:426-31.

40 Zhang Y, Ting RZ, Yang W, et al. Depression in Chinese patients with type 2 diabetes: associations with hyperglycemia, hypoglycemia, and poor treatment adherence. J Diabetes 2015;7:800-8.

41 Boucher MC, El Yamani MEM. Urban diabetic retinopathy teleophthalmology screening: results and impact at the service corridor. Can J Ophthalmol 2019;54:359-66.

42 Scarpa G, Urban F, Vujosevic S, et al. The nonmydriatic fundus camera in diabetic retinopathy screening: a cost-effective study with evaluation for future large-scale application. J Ophthalmol 2016;2016:4625096:7. 